\title{
Sleep apnea prevalence in chronic kidney disease - association with total body water and symptoms
}

\author{
Hsin-Chia Huang ${ }^{1,3^{*}}$, Giles Walters ${ }^{2,3}$, Girish Talaulikar ${ }^{2,3}$, Derek Figurski ${ }^{1}$, Annette Carroll ${ }^{1}$, Mark Hurwitz ${ }^{1,3}$,
} Krishna Karpe ${ }^{2,3}$ and Richard Singer ${ }^{2,3}$ (D)

\begin{abstract}
Background: Sleep apnea is common and associated with poor outcome in severe chronic kidney disease, but validated screening tools are not available. Our objectives were to determine the prevalence of sleep apnea in this population, to assess the validity of screening for sleep apnea using an ApneaLink device and to investigate the relationship of sleep apnea to; symptoms, spirometry and body water.

Methods: Patients with glomerular filtration rate $\leq 30 \mathrm{~mL} / \mathrm{min} / 1.73 \mathrm{~m}^{2}$, whether or not they were receiving haemodialysis, were eligible for enrolment. Participants completed symptom questionnaires, performed an ApneaLink recording and had total body water measured using bioimpedance. This was followed by a multi-channel polysomnography recording which is the gold-standard diagnostic test for sleep apnea.

Results: Fifty-seven participants were enrolled and had baseline data collected, of whom only 2 did not have sleep apnea. An apnea hypopnea index $\geq 30 / \mathrm{h}$ was found in $66 \%$ of haemodialysis and $54 \%$ of non-dialysis participants. A central apnea index $\geq 5 / \mathrm{h}$ was present in 11 patients, with only one dialysis patient having predominantly central sleep apnea. ApneaLink underestimated sleep apnea severity, particularly in the non-dialysis group. Neither total body water corrected for body size, spirometry, subjective sleepiness nor overall symptom scores were associated with sleep apnea severity.

Conclusions: This study demonstrates a very high prevalence of severe sleep apnea in patients with chronic kidney disease. Sleep apnea severity was not associated with quality of life or sleepiness scores and was unrelated to total body water corrected for body size. Routine identification of sleep apnea with polysomnography rather than screening is more appropriate in this group due to the high prevalence.
\end{abstract}

Keywords: Body water, Chronic kidney failure, Quality of life, Renal dialysis, Sleep

\section{Background}

Sleep apnea is defined as an apnea-hypopnea index (AHI) $\geq 5$ episodes per hour in symptomatic patients or $\geq 15$ obstructive episodes per hour in asymptomatic patients $[1,2]$. Sleep apnea severity is determined by the degree of sleepiness and by the AHI [1]. Determining whether symptoms of sleep apnoea are present is problematic in patients with severe kidney failure since some accepted symptoms such as unrefreshing, restless sleep and fatigue

\footnotetext{
* Correspondence: Richard.singer@act.gov.au

'Department of Respiratory and Sleep Medicine, The Canberra Hospital, Garran, ACT, Australia

${ }^{3}$ The Australian National University Medical School, Acton, ACT, Australia Full list of author information is available at the end of the article
}

are often reported by patients with severe chronic kidney disease (CKD), even in the absence of significant sleep apnea $[3,4]$. Other symptoms such as nocturia [2] cannot be present in anuric dialysis patients or may be present but unrelated to sleep apnoea in severe, non dialysis kidney failure. These issues make symptom based screening questionnaires less discriminatory in a CKD population [5] and for this reason a sleep apnea definition of $\mathrm{AHI} \geq 5$, irrespective of symptoms is used in this study.

The prevalence of apparently asymptomatic sleep disordered breathing in non-CKD women and men is increasing in prevalence and is thought to be approximately $26 \%$ of the US adult population [6, 7]. Sleep apnea is a risk factor for the development of CKD, progression of CKD 
[8] and is associated with cognitive impairment in those with CKD [9]. Treatment in the non-CKD population is associated with lower blood pressure [10] and perhaps with improved survival, [11] but the effect in those with CKD is unknown. A high prevalence of sleep apnea has been recognized in patients with CKD since the 1980s with the prevalence of severe sleep apnea $(\mathrm{AHI} \geq 30)$ reported to be present in 20\% of those with severe nondialysis CKD and $26 \%$ of those on hemodialysis [12]. Other studies, of varying quality, have reported a prevalence for $\mathrm{AHI} \geq 5$ in those on hemodialysis of between 50 and $83 \%$ [13-16] and there is data to suggest that a lower estimated glomerular filtration rate (eGFR) is associated with more severe sleep apnea in CKD patients [17].

Severe muscle weakness and fluid retention have been proposed as explanations for the high prevalence of sleep apnea in CKD patients. Airway muscle weakness makes airways more prone to collapse on inspiration, whereas fluid retention appears to result in swelling of airway walls and therefore increases the resistance to airflow and propensity to collapse [18]. In accordance with this, obstructive lung disease in non-dialysis patients [19] and fluid overload in CKD patients [20, 21] have been associated with more severe nocturnal hypoxaemia.

The gold standard for diagnosis of sleep apnea is an attended overnight polysomnogram (PSG), [22] but this is a labour intensive and costly investigation. Limited channel recordings such as ApneaLink (ResMed Corp, Poway, California), provide some information on respiratory parameters, but no information on duration of sleep. These devices are available to screen for the presence of sleep apnea in some settings, [23] but have not been validated in a CKD population. Availability of a validated screening device may enable a cost-effective screening programme for sleep apnea to be developed in the CKD population.

The objectives of this study were to determine the prevalence of sleep apnea in a severe CKD population, to assess the validity of screening for sleep apnea using an ApneaLink device and to investigate the relationship of sleep apnea to; symptoms, spirometry and body water.

\section{Methods}

The Canberra Hospital is a publicly funded 600 bed tertiary hospital servicing a population of approximately 570000 . Patients were approached for enrolment if they were; ambulant, aged over 18 years, under the care of the Canberra Hospital Renal Service, and had an eGFR by 3 variable MDRD formula [24] of $<30 \mathrm{~mL} / \mathrm{min} / 1.73 \mathrm{~m}^{2}$. For those receiving haemodialysis, they must have been established on haemodialysis for at least 3 months. Participants were excluded if they; had been hospitalized within the previous month, were unable or unwilling to provide informed consent, had previously diagnosed sleep apnea, usually received greater than $18 \mathrm{~h}$ haemodialysis per week or were treated with peritoneal dialysis. Enrolment was planned to continue until at least 50 subjects had undergone a PSG, split equally between the haemodialysis and non-dialysis groups. This number was based on available funding and investigator expectations of dialysis patient consent rates. Patients that declined to participate were asked during the consent process whether they rated their sleep as "good" or "poor". As recommended in guidelines for this type of study, patients formed a consecutive series and were not selected or approached based on the presence or absence of symptoms, co-morbidities, sex or age [25].

At the initial study visit data on; height, neck circumference most recent post-dialysis weight (or current weight for non-dialysis subjects), eGFR and smoking history were collected. Data on subject race was not collected as previous studies in patients with severe renal failure at the same institution demonstrated that subjects were often either unwilling to answer questions regarding ethnic/racial origin or gave ambiguous answers that required categorisation by the investigators. For this reason, as is standard for automated eGFR reporting in Australia, race was set to "white". Body mass index (BMI) was calculated as Weight $(\mathrm{kg})$ /Height $(\mathrm{m})^{2}$. Participants were also given; the Kidney Dialysis Quality of Life-Short Form [26] (KDQOL-SF), Epworth Sleepiness Scale [27] and a modified Berlin Questionnaire [28] to complete.

The Berlin Questionnaire asks about the presence of snoring, sleepiness and hypertension. A positive score in 2 out of the 3 symptom domains denotes a high risk for sleep apnea. Since hypertension and/or use of antihypertensives were universal in the study group and thus nondiscriminatory, we modified the Berlin Questionnaire to exclude hypertension from the scoring. The Epworth Sleepiness Scale assesses the likelihood of falling asleep during common activities. Persons without sleep disorders have a mean score of approximately 6 out of 24 [27].

Participants were shown how to use the ApneaLink device, and took it home for a self-administered overnight recording within 6 weeks of collection of baseline data. The ApneaLink is a Type 4 limited channel recording device [29] that measures nasal airflow and oximetry only. Output was auto-analysed using software provided by the manufacturer.

To avoid delaying treatment of participants with potentially severe sleep apnea, those that were "High Risk" on the Berlin Questionnaire, or who had an ApneaLink AHI $\geq 10$, or who had an Epworth score $\geq 10$ and an ApneaLink AHI $\geq 5$ were seen by a sleep physician within 1 week. An overnight PSG was performed in all participants 1 week after the ApneaLink. Both the ApneaLink and PSG were performed on the same day of the week and in all cases this was on an evening immediately following a dialysis session (for hemodialysis participants). Haemodialysis participants attended an in-lab PSG (E-Series, Compumedics, Melbourne, Australia), whereas an unattended PSG 
(SomtePSG, Compumedics, Melbourne, Australia) was performed in non-dialysis participants. Investigators were not blinded to the ApneaLink and clinical data. The sleep scoring was performed using the Compumedics ProFusion 3 software in accordance with AASM criteria [30]. Central sleep apnea index (CAI) was defined as the number of central apneas per hour of sleep.

Spirometry and body water was measured on the day of the sleep study by a trained technician (post dialysis for haemodialysis participants). Spirometry was performed and reported according to ATS/ERS guidelines [31]. Body water was estimated using bioimpedance (BCM, Fresenius Health Care, Bad Homburg, Germany) [32]. To reduce the dependence of total body water on body size, total body water was divided by body weight (referred to as body water fraction) or height squared. The post-dialysis weight was used in haemodialysis participants. As female dialysis patients have a lower body water fraction than males, [33] analysis was performed separately in males and females. Spirometry was measured using the EasyOne (Medizintechnik, Switzerland) spirometer with predictive normal values based on the 3rd National Health and Nutrition Examination Survey [34].

For the purposes of assessing selection bias in participant recruitment, the study population was considered to be haemodialysis and severe non-dialysis CKD patients serviced by The Canberra Hospital Renal Service as at 31st December, 2013.

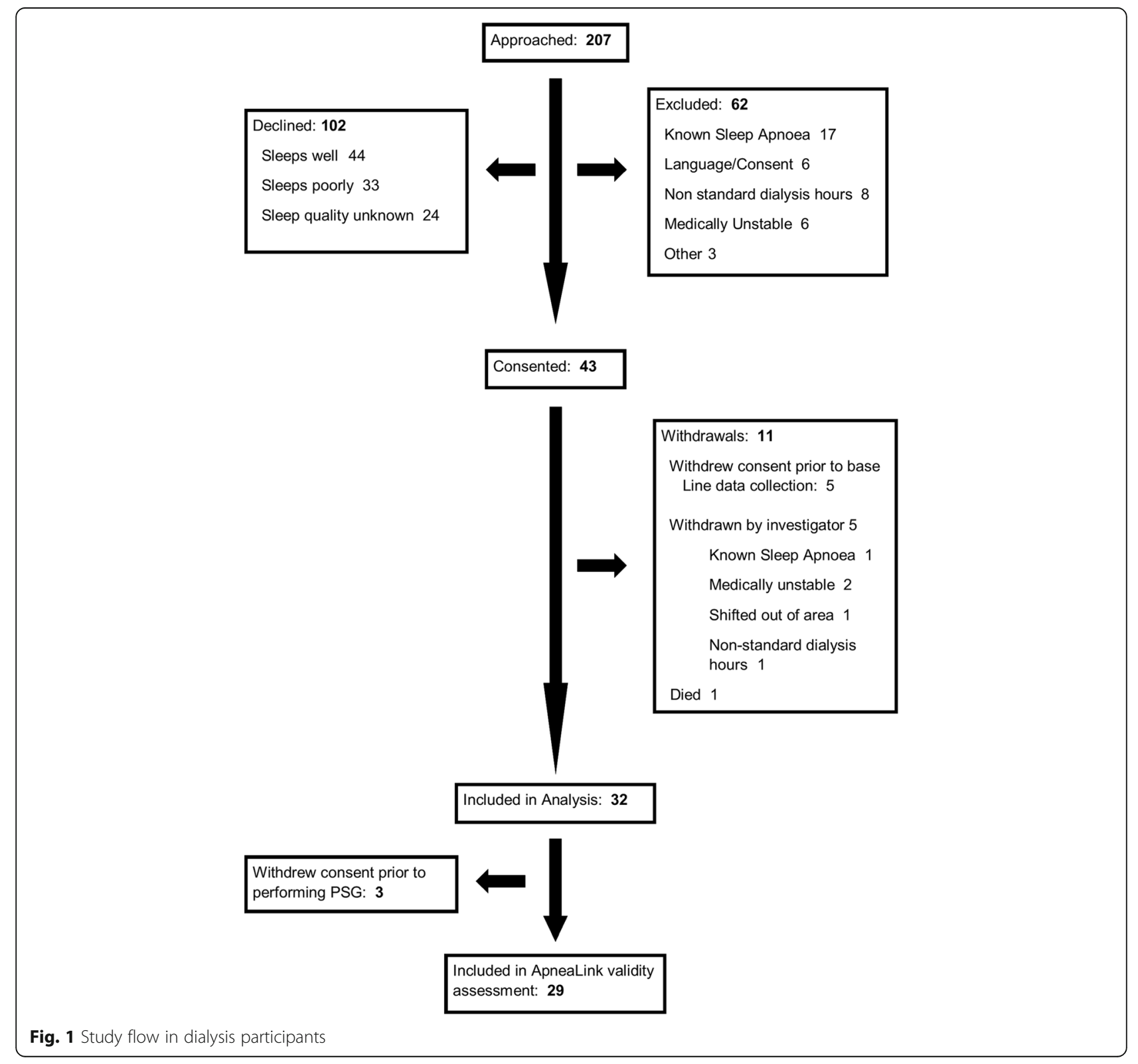




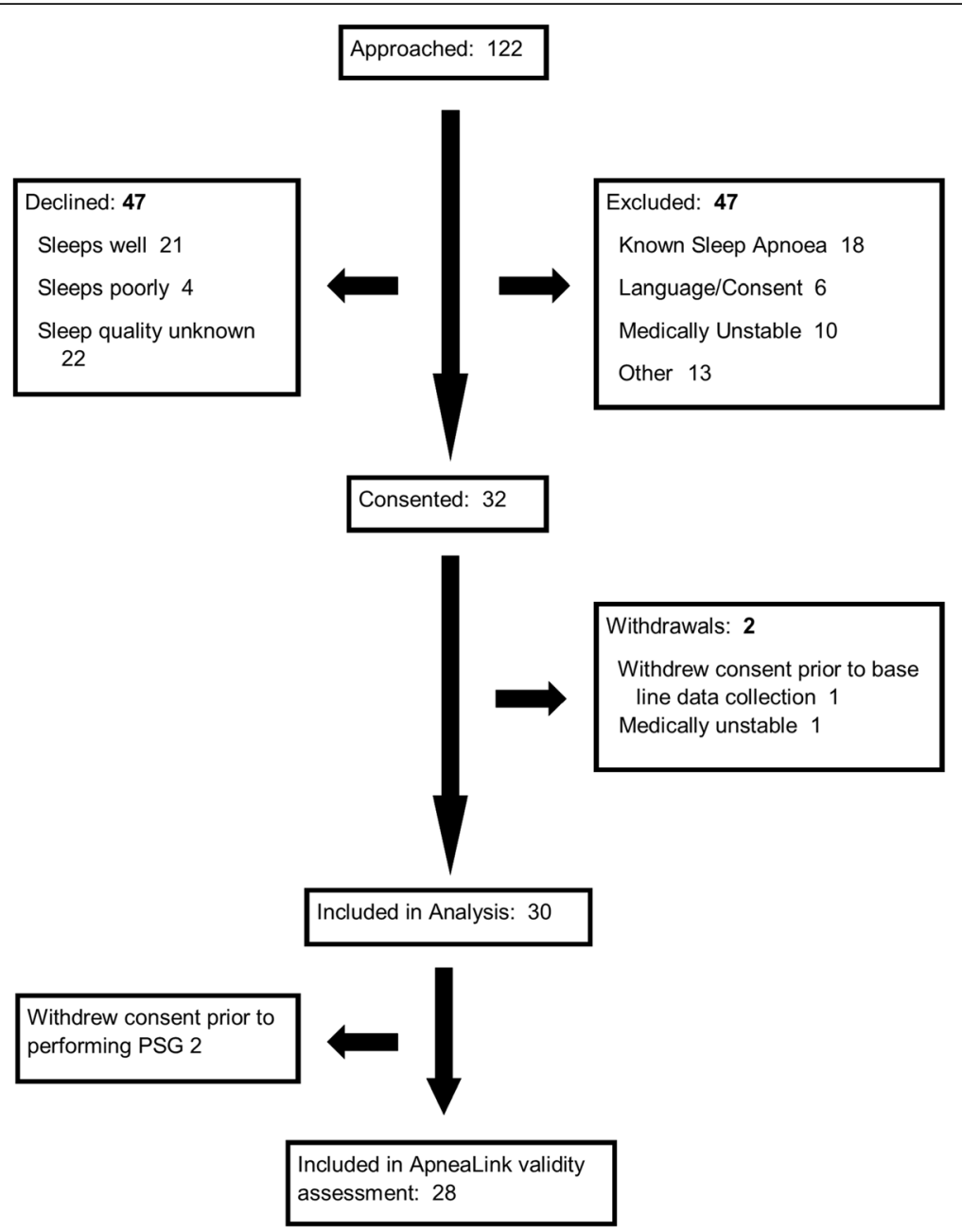

Fig. 2 Study flow in non-dialysis participants

Table 1 Baseline Characteristics

\begin{tabular}{|c|c|c|c|}
\hline & $\begin{array}{l}\text { Dialysis Group } \\
(n=32)\end{array}$ & $\begin{array}{l}\text { Non-Dialysis } \\
\text { Group }(n=30)\end{array}$ & $P$ value \\
\hline Age (years) & 65.5 (50 to 71.5 ) & 71 (55 to 78 ) & 0.11 \\
\hline Male/Female & $29 / 3$ & $22 / 7$ & 0.12 \\
\hline $\mathrm{BMI}\left(\mathrm{kg} / \mathrm{m}^{2}\right)$ & 26.8 (24.1 to 30.9 ) & 29.5 (25.2 to 32.6 ) & 0.13 \\
\hline $\begin{array}{l}\text { Neck Circumference } \\
(\mathrm{cm})\end{array}$ & 41 (38 to 45.5$)$ & 39.5 (38 to 42 ) & 0.05 \\
\hline eGFRmL/min/1.73 m² & & $21.2 \pm 5.6$ & \\
\hline Dialysis dose (Kt/N) & $1.32 \pm 0.18$ & & \\
\hline Dialysis Vintage (years) & 1.8 (1.1 to 3.7$)$ & & \\
\hline $\begin{array}{l}\text { Epworth Sleepiness } \\
\text { Scale }\end{array}$ & $8(5$ to 10$)$ & 7 (6 to 10$)$ & 0.79 \\
\hline $\begin{array}{l}\text { Epworth Sleepiness } \\
\text { Scale } \geq 10\end{array}$ & $10(31 \%)$ & $8(27 \%)$ & 0.69 \\
\hline $\begin{array}{l}\text { High Risk Category } \\
\text { on modified Berlin } \\
\text { Questionnaire }\end{array}$ & $34 \%$ & $40 \%$ & 0.79 \\
\hline
\end{tabular}

\section{Statistics}

Normally distributed data is presented as mean \pm standard deviation and non-normally distributed data as median (interquartile range). Raw or transformed data distribution was tested using the Shapiro-Wilk and Levene's tests. Agreement was tested using Cohen's kappa. Differences in means and medians were tested by $t$-test, ANOVA, Wilcoxon Rank-Sum or Kruskal-Wallis Rank test as appropriate. Nominal variables were tested by Fisher Exact test. Statistical significance was set at a $p$ value of $<0.05$, with all $p$ values 2sided except when inappropriate (in $>2$ way contingency tables). Significance level was not adjusted for multiple testing.

\section{Results}

Participant flow through screening, enrolment and consent procedures are shown in Figs. 1 and 2. A total of 32 nondialysis patients consented to enrol during the non-dialysis recruitment period (September 2012 to November 2013). Two participants left the study prior to collection of baseline data and were not included in data analysis. Another 2 
Table 2 Study Sample Compared to Study Population

\begin{tabular}{|c|c|c|c|c|c|c|}
\hline & $\begin{array}{l}\text { Haemodialysis Population } \\
(n=266)\end{array}$ & $\begin{array}{l}\text { Haemodialysis Study } \\
\text { Sample }(n=32)\end{array}$ & $p$ value & $\begin{array}{l}\text { Non-dialysis Population } \\
(n=435)\end{array}$ & $\begin{array}{l}\text { Non-Dialysis Study } \\
\text { Sample }(n=30)\end{array}$ & $p$ value \\
\hline Age & 66 (55 to 76$)$ & 65.5 (50 to 71.5$)$ & 0.33 & 72 (62 to 80 ) & 71 (55 to 78) & 0.42 \\
\hline BMI & 26.3 (22.3 to 30.6$)$ & 26.8 (24.1 to 30.9$)$ & 0.36 & 28.3 (24.9 to 32.2 ) & 29.5 (25.2 to 32.6$)$ & 0.46 \\
\hline$\%$ Male & $64 \%$ & $91 \%$ & 0.002 & $55 \%$ & $73 \%$ & 0.003 \\
\hline
\end{tabular}

participants withdrew following partial collection of baseline data, but before performing polysomnography. These participants were included in the analyses for collected data.

A total of 43 haemodialysis patients consented to enrol during the haemodialysis recruitment period (May 2010 to January 2012). Eleven participants left the study prior to collection of baseline data and were not included in data analysis. Another 3 participants withdrew following partial baseline data collection, but before performing the polysomnography. These participants are included in the analyses for collected data.

Participant baseline characteristics are summarised in Table 1 . The majority were not obese, but were relatively sleepy, with close to $30 \%$ in each group having Epworth scores of $\geq 10$. A similar proportion of dialysis and nondialysis participants were categorized as "high risk" for sleep apnea by the modified Berlin Questionnaire.

Males were significantly over-represented in the study sample, but median age and BMI were similar to those seen in the study population (Table 2).

Ninety-six percent of participants had some degree of sleep disordered breathing and this was predominantly obstructive. Significant central sleep apnea - a central apnea

Table 3 ApneaLink and PSG Sleep data

\begin{tabular}{|c|c|c|c|c|}
\hline & $\begin{array}{l}\text { Dialysis } \\
\text { Group }\end{array}$ & $\begin{array}{l}\text { Non-Dialysis } \\
\text { Group }\end{array}$ & Overall & $\begin{array}{l}p \text { value } \\
\text { (Dialysis vs } \\
\text { Non Dialysis) }\end{array}$ \\
\hline $\begin{array}{l}\text { ApneaLink } \\
\text { AHI }\end{array}$ & $\begin{array}{l}22.5 \\
(12 \text { to } 41.5)\end{array}$ & $\begin{array}{l}12.5 \\
\text { (4 to } 33 \text { ) }\end{array}$ & $\begin{array}{l}19.5 \\
\text { (7 to 38) }\end{array}$ & 0.028 \\
\hline $\begin{array}{l}\text { ApneaLink } \\
\mathrm{AHI} \geq 15\end{array}$ & 21 (66\%) & 14 (47\%) & 35 (56\%) & 0.2 \\
\hline PSG AHI & $\begin{array}{l}37.6 \\
\text { (23.1 to } 77.2 \text { ) }\end{array}$ & $\begin{array}{l}34.4 \\
\text { (19.6 to } 58.7 \text { ) }\end{array}$ & $\begin{array}{l}35.3 \\
(20.5 \text { to } 69.1)\end{array}$ & 0.24 \\
\hline PSG AHI $<5$ & $1(3 \%)$ & $1(4 \%)$ & $2(4 \%)$ & \multirow{4}{*}{$\begin{array}{l}0.62 \\
\text { (one tailed) }\end{array}$} \\
\hline $\begin{array}{l}\text { PSG AHI } \\
5 \text { to }<15\end{array}$ & $5(17 \%)$ & $4(14 \%)$ & $9(16 \%)$ & \\
\hline $\begin{array}{l}\text { PSG-AHI } \\
15 \text { to }<30\end{array}$ & $4(14 \%)$ & $8(29 \%)$ & $12(21 \%)$ & \\
\hline $\begin{array}{l}\text { PSG-AHI } \\
\geq 30\end{array}$ & 19 (66\%) & 15 (54\%) & $34(60 \%)$ & \\
\hline $\begin{array}{l}\text { PSG AHI } \\
\geq 15\end{array}$ & $23(79 \%)$ & 23 (82\%) & 46 (81\%) & 1 \\
\hline PSG CAI & $\begin{array}{l}0.7 \\
\text { (0.4 to } 5.4 \text { ) }\end{array}$ & $\begin{array}{l}0.35 \\
\text { (0 to 1.5) }\end{array}$ & $\begin{array}{l}0.6 \\
\text { (0.2 to } 2.3)\end{array}$ & 0.04 \\
\hline PSG CAI $\geq 5$ & 9 (31\%) & $2(7 \%)$ & 11 (19\%) & 0.02 \\
\hline
\end{tabular}

index $\geq 5 / h$ by PSG- was present in 11 patients, most of whom were in the dialysis group. Only one dialysis patient had predominantly central sleep apnea, with CAI of $88 / \mathrm{h}$. Most participants were severely hypoxic at some point during sleep. The median nadir oxygen saturation was $80 \%$ and the median percentage of sleep time spent below $90 \%$ oxygen saturation was $4 \%$ (IQR 7 to $19 \%$ ). The median periodic leg movements index (PLMI) was low in both groups $(2 / \mathrm{h})$ but $25 \%$ of patients still had a PLMI of $\geq 15 / \mathrm{h}$. Sleep onset latency and sleep efficiency was similar in both groups. The ApneaLink and PSG derived data is summarised in Table 3.

The sensitivity and specificity of ApneaLink for categorizing participants as having an $\mathrm{AHI} \geq 15$ is summarised in Table 4. Agreement between ApneaLink and PSG determined sleep apnea severity category was moderate in the dialysis group, (kappa $=0.39, p=0.0004$ ) but low and not statistically different from chance in the non-dialysis group, (kappa $=0.1, p=0.15)$. Agreement improved for identifying moderate and severe sleep apnea (AHI $\geq 15)$, with kappa of $0.32,(p=0.01)$ in the non-dialysis group and kappa of $0.63(p=0.0003)$ in the dialysis group. ApneaLink underestimated the AHI in all but 7 participants, all of whom were in the dialysis group (Fig. 3).

Higher BMI and neck circumference correlated with a higher AHI in non-dialysis participants, but not in those on dialysis (Table 5). Age was not statistically associated with sleep apnea severity in either group.

Spirometry data, expressed as a percentage of predicted values based on age, sex and height, is summarized in Table 6. Dialysis participants had more restrictive spirometry, particularly in the 5 patients with $\mathrm{AHI}<15$.

Non-dialysis participants with AHI $\geq 15$ recorded improved quality of social interaction (score of 86 compared to $66, p=0.03$ ) and a trend towards improved sleep (score of 62 compared to 47, $p=0.051$ ). Aside from this, sleep apnea severity was not associated changes in any domain of the KDQOL-SF. Neither the modified Berlin Questionnaire,

Table 4 Test characteristic of ApneaLink for $\mathrm{AHI} \geq 15$

\begin{tabular}{lllll}
\hline & Sensitivity & Specificity & $\begin{array}{l}\text { Positive } \\
\text { Predictive } \\
\text { Value }\end{array}$ & $\begin{array}{l}\text { Negative } \\
\text { Predictive } \\
\text { Value }\end{array}$ \\
\hline Overall & $72 \%$ & $91 \%$ & $97 \%$ & $43 \%$ \\
Dialysis group & $87 \%$ & $83 \%$ & $95 \%$ & $63 \%$ \\
Non-dialysis group & $57 \%$ & $100 \%$ & $100 \%$ & $33 \%$ \\
\hline
\end{tabular}




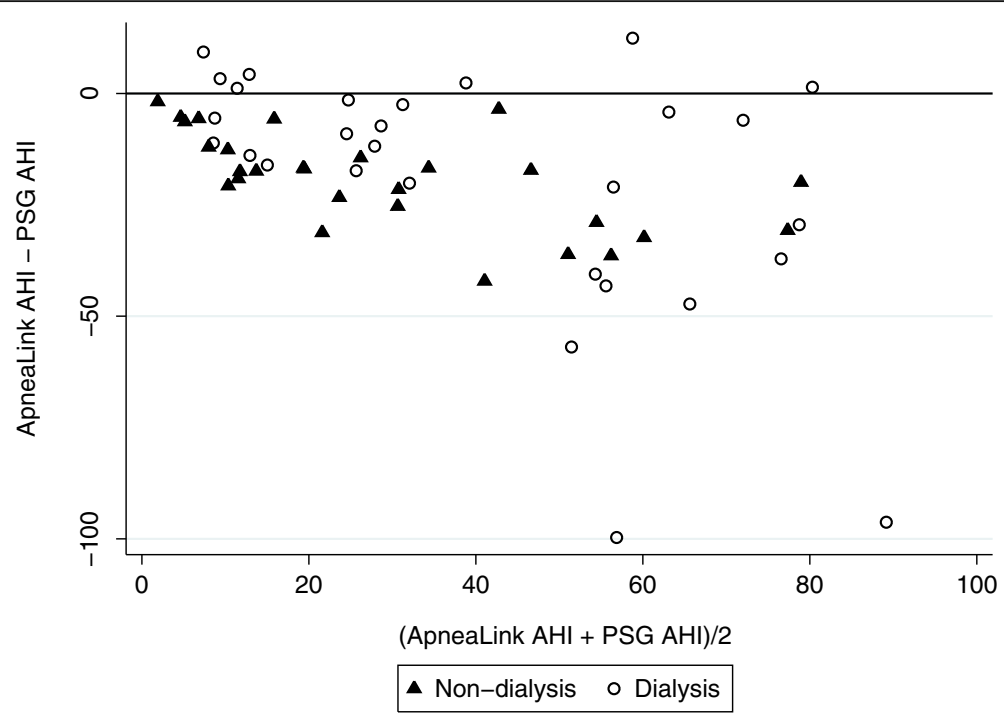

Fig. 3 Bland-Altman plot of ApneaLink and PSG AHI

nor the Epworth Sleepiness Scale discriminated between those with less, or more severe sleep disordered breathing.

There was no difference in the body water fraction between male dialysis participants and non-dialysis participants, and no association to sleep apnea severity or to the presence of central sleep apnea (Table 7). Analysis of female participants was not performed due to the very small sample size. Using height, or height squared, rather than total body weight, to correct for body size did not alter these findings. Similarly, no relationship was seen between fat mass or extra-cellular fluid mass as a fraction of body weight and sleep apnea severity. Data for the single participant with severe central sleep apnea $(\mathrm{CAI}=88)$ indicated that his body water fraction was similar to the group median.

\section{Discussion}

We found a very high, 96\%, prevalence of sleep disordered breathing and $80 \%$ of participants had moderate or severe sleep apnea $(\mathrm{AHI} \geq 15)$. These prevalence figures are higher than most previous reports [12, 14-16] Central sleep apnea was much more common in haemodialysis compared to non-dialysis participants (31\% versus $7 \%$ ), but $\mathrm{CAI} \geq 30$ was present in only a single patient. The reported prevalence for central sleep apnea in subjects with CKD was 0 to $75 \%$ in a recent systematic review [35]. However, this range is unhelpful in drawing firm

Table 5 Correlation of BMI and neck circumference to AHI

\begin{tabular}{llllll}
\hline & \multicolumn{2}{l}{$\begin{array}{l}\text { Dialysis } \\
\text { Group }(n=28)\end{array}$} & & & $\begin{array}{l}\text { Non Dialysis } \\
\text { Group }(n=29)\end{array}$ \\
\cline { 2 - 3 } & Spearman rho & $p$ value & & Spearman rho & $p$ value \\
\hline BMI & 0.2 & 0.29 & & 0.48 & 0.01 \\
Neck Circumference & 0.36 & 0.06 & & 0.67 & 0.0001 \\
\hline
\end{tabular}

conclusions on prevalence since the definition of sleep apnea varied across studies included in the review and the study with $75 \%$ prevalence was based on only 8 subjects [35].

Our overall enrolment rate was lower than several other publications, which reported recruitment rates of $50-67 \%[5,16,21,36]$. We enrolled only $40 \%$ of patients approached in the non-dialysis group and $22 \%$ in the haemodialysis group. The non-dialysis enrolment rate is, however, similar to that seen in the large Wisconsin Sleep Cohort study [6]. We attempted to obtain a representative sample from the study population but were unsuccessful, particularly in the haemodialysis group, where a substantial excess of men enrolled. Previous studies in dialysis patients have also enrolled an excess of men, $[5,16,36]$ but it is uncertain if this was due to selection bias since the composition of their study populations were not reported. The male enrolment proportion in those studies (approximately 70\%) is substantially lower than the $91 \%$ seen in our study. Despite our study sample mirroring the research population for the other demographic variables collected, it is likely that the prevalence data is biased, since sleep apnea is thought to be much more common in men [6].

It is unclear why women were difficult to enrol. Perhaps potential male participants felt they were likely to have sleep apnea due to symptoms that were not captured in our questionnaires and therefore they had a greater incentive to participate. The minimum estimated sleep apnea prevalence in the study population was $28 \%$ (non-dialysis) and 48\% (dialysis) when those known to have sleep apnea were included. In this calculation nonconsenting potential subjects were assumed not to have sleep apnea and were included in the denominator. 
Table 6 Association of Spirometry Data with PSG AHI

\begin{tabular}{|c|c|c|c|c|c|c|}
\hline & \multicolumn{3}{|c|}{ Dialysis Group $(n=28)$} & \multicolumn{3}{|c|}{ Non-Dialysis Group $(n=24)$} \\
\hline & $\mathrm{AHI}<15(n=5)$ & $\mathrm{AHI}>=15(n=23)$ & $p$ value & $\mathrm{AHI}<15(n=5)$ & $\mathrm{AHI}>=15(n=18)$ & $p$ value \\
\hline $\begin{array}{l}\text { FEV1 } \\
\text { (\% predicted) }\end{array}$ & $59 \pm 12$ & $75 \pm 16$ & 0.047 & $79 \pm 22$ & $82 \pm 18$ & 0.78 \\
\hline $\begin{array}{l}\text { FVC } \\
\text { (\% predicted) }\end{array}$ & $59 \pm 5$ & $73 \pm 15$ & 0.07 & $84 \pm 13$ & $77 \pm 15$ & 0.32 \\
\hline FEV1/FVC & $75 \pm 12$ & $79 \pm 5$ & 0.30 & $72 \pm 11$ & $78 \pm 9$ & 0.16 \\
\hline
\end{tabular}

Traditional risk factors of higher BMI and neck circumference were associated with more severe sleep apnea in non-dialysis participants but not in dialysis participants. This suggests a different mechanism promoting sleep apnea may be present in those on dialysis, compared to the CKD or normal population.

It has been reported that pharyngeal caliber responds to diuretic induced fluid removal during the treatment of heart failure and that sleep apnea severity improves with fluid removal in newly initiated peritoneal dialysis patients [20, 37]. In newly initiated peritoneal dialysis patients pharyngeal edema is associated with more severe sleep apnea but a relationship to total body water in that study was not reported [20]. The subjects in that study were of lower body weight and higher body water fraction (approximately $62 \%$ ) than subjects in our study. In contrast, we found that bioimpedance determined total body water as a proportion of body size was not predictive of sleep apnea severity. It is likely that total body bioimpedance measurements are either not sufficiently sensitive to detect changes in the pharyngeal edema or alternatively, that total body water is only a minor determinant of sleep apnea severity in patients with severe kidney failure. It is a limitation of our study that pharyngeal fluid was not directly assessed, and hence the relationship to total body water could not be confirmed.

The ApneaLink AHI was lower than PSG derived AHI in all but 7 participants, most likely because the screening device cannot distinguish sleep from wakefulness. It was not possible to validate the ApneaLink device as a screening tool for the presence of sleep apnea because so few participants had a normal AHI. However, unlike symptom questionnaires (which other investigators have also noted to be inaccurate in CKD [5]) the device had good agreement with PSG in detecting participants with $\mathrm{AHI} \geq 15$. Agreement was, however, only fair in non- dialysis participants and ApneaLink appeared unsatisfactory as a screening tool for this group. The specificity and negative predictive values reported in Table 4 should be treated with caution due to the high dependency on results in only a few patients. The relatively low negative predictive values in a population with very high prevalence indicates that, despite the good agreement seen in haemodialysis participants, ApneaLink screening is unlikely to be useful, and patients should proceed directly to polysomnography.

We did not find evidence of worse scores in the symptom or other KDQOL-SF domains in participants who had more severe sleep apnea. Participants were very symptomatic in terms of the average Epworth Sleepiness Scale scores but there was no evidence of greater sleepiness or impaired subjective cognition in those with higher AHIs. In fact, the apparent direction of some statistically significant associations was towards improved quality of life in those with more severe sleep apnea. These statistical associations are probably due to chance, especially since we applied multiple statistical tests in this study. There is no plausible explanation why more severe sleep apnea should improve any aspect of quality of life. Our results suggest that neither the KDQOL-SF nor the Epworth Sleepiness Scale is sensitive to changes AHI. Similar results with respect to the Epworth Sleepiness Scale have been reported in a similar CKD population [12]. We did not screen for restless leg syndrome, but a quarter of participants had $\geq 15$ leg movements/h) - which is a somewhat lower rate than reported in a previous study in dialysis patients [16].

\section{Conclusions}

Systematic identification of sleep apnea in CKD patients should be considered given that it is associated with a poor outcome $[8,9]$ however we were unable to validate

Table 7 Body Water Fraction and Severity of Sleep Apnea in Males

\begin{tabular}{|c|c|c|c|c|c|c|c|c|c|}
\hline \multirow[b]{2}{*}{$\mathrm{AHI}$} & \multicolumn{2}{|l|}{ Overall $(n=39)$} & \multirow[b]{2}{*}{ p } & \multicolumn{2}{|c|}{ Dialysis group $(n=15)$} & \multirow[b]{2}{*}{$p$} & \multicolumn{2}{|c|}{ Non-dialysis group $(n=24)$} & \multirow[b]{2}{*}{$p$} \\
\hline & $<15$ & $\geq 15$ & & $<15$ & $\geq 15$ & & $<15$ & $\geq 15$ & \\
\hline $\begin{array}{l}\text { Body water fraction } \\
(\mathrm{L} / \mathrm{Kg})\end{array}$ & $\begin{array}{l}0.50 \\
(0.49 \text { to } 0.54)\end{array}$ & $\begin{array}{l}0.46 \\
(0.44 \text { to } 0.51)\end{array}$ & 0.22 & $\begin{array}{l}0.54 \\
(0.42 \text { to } 0.55)\end{array}$ & $\begin{array}{l}0.47 \\
(0.43 \text { to } 0.49)\end{array}$ & 0.32 & $\begin{array}{l}0.50 \\
(0.49 \text { to } 0.50)\end{array}$ & $\begin{array}{l}0.46 \\
(0.45 \text { to } 0.52)\end{array}$ & 0.87 \\
\hline $\begin{array}{l}\text { Body Water/Height }{ }^{2} \\
\left(\mathrm{~L} / \mathrm{m}^{2}\right)\end{array}$ & $\begin{array}{l}12.9 \\
(11.8 \text { to } 15.8)\end{array}$ & $\begin{array}{l}13.0 \\
(11.9 \text { to } 14.2)\end{array}$ & 0.97 & $\begin{array}{l}11.8 \\
(9.4 \text { to } 17.5)\end{array}$ & $\begin{array}{l}12.5 \\
(10.9 \text { to } 13.2)\end{array}$ & 0.76 & $\begin{array}{l}14.3 \\
(12.9 \text { to } 15.8)\end{array}$ & $\begin{array}{l}14 \\
(13.4 \text { to } 15.4)\end{array}$ & 0.87 \\
\hline
\end{tabular}


the ApneaLink device as a screening tool in this population due to the very high prevalence of sleep disordered breathing. The lack of an association between sleep apnea severity and symptom questionnaires does not mean that participants were asymptomatic. A more plausible explanation is that these instruments are insensitive to the effects sleep apnea in patients with severe CKD. Therefore, future intervention studies performed in this population will likely need to utilize other instruments, or alternative end points such as progression of renal disease to assess the effectiveness of therapy. Our results suggest that measures of total body water are not associated with sleep apnea severity in this population.

\section{Additional files}

Additional file 1: Study sample data. (XLSX $51 \mathrm{~kb}$ )

Additional file 2: Comparison data of study population to the study sample. (XLSX 26 kb)

\section{Abbreviations}

AHI: Apnea hypopnea index; CAl: Central apnea index; CKD: Chronic kidney disease; KDOOL-SF: Kidney disease quality of life instrument- short form; PSG: Poly somnogram

\section{Acknowledgements}

The authors acknowledge the work of Patricia Johnson, research assistant, in enrolment and data collection. This study was funded by The Canberra Hospital Private Practice Fund. The ApneaLink device used was provided by ResMed Corp, Poway, California. The authors are solely responsible for data analysis, writing of the manuscript and the decision to publish.

\section{Funding}

This study was funded by a grant from The Canberra Hospital Private Practice Fund.

\section{Availability of data and materials}

Datasets supporting the conclusions of this article are included within the article and its Additional files 1 and 2. To ensure subject anonymity the age, date of birth and information that would allow dialysis commencement date to be determined are not included.

\section{Authors' contributions}

$\mathrm{HCH}$ and RS conceived the study. $\mathrm{HCH}$ assessed all the participants medically, reviewed polysomnography and offered treatment to participants found to have sleep apnea. AC conducted and analysed the polysomnography, DF and $\mathrm{MH}$ performed and reported the spirometry, GT performed the bioimpedance, GW built the database which housed study data, RS analysed the data and wrote the initial draft manuscript. All authors were involved in study design and in ensuring data integrity. All authors read and approved the final manuscript.

\section{Competing interests}

ResMed Corp, Poway, California provided, at no charge, an ApneaLink device for use in the study. The authors declare that they have no other competing interests.

\section{Consent for publication}

This study does not contain individual person's data so consent to publish is not applicable.

\section{Ethics approval and consent to participate}

This study was approved by the ACT Health Human Research Ethics Committee (ETH.10.08.939) and all participants provided written informed consent prior to enrolment.

\section{Publisher's Note}

Springer Nature remains neutral with regard to jurisdictional claims in published maps and institutional affiliations.

\section{Author details}

${ }^{1}$ Department of Respiratory and Sleep Medicine, The Canberra Hospital, Garran, ACT, Australia. ${ }^{2}$ Department of Renal Medicine, The Canberra Hospital, Garran, ACT, Australia. ${ }^{3}$ The Australian National University Medical School, Acton, ACT, Australia.

Received: 5 June 2016 Accepted: 28 March 2017

Published online: 04 April 2017

\section{References}

1. American academy of sleep medicine task force. Sleep-related breathing disorders in adults: recommendations for syndrome definition and measurement techniques in clinical research. The Report of an American Academy of Sleep Medicine Task Force. Sleep. 1999;22(5):667-89.

2. Adult Obstructive Sleep Apnea Task Force of the American Academy of Sleep M. Clinical Guideline for the Evaluation, Management and Long-term Care of Obstructive Sleep Apnea in Adults. J Clin Sleep Med. 2009;5(3):263-76.

3. Parker KP, Bliwise DL, Bailey $\mathrm{L}$, Rye DB. Polysomnographic measures of nocturnal sleep in patients on chronic, intermittent daytime haemodialysis vs those with chronic kidney disease. Nephrol Dial Transplant. 2005:20(7):1422-8.

4. Miśkowiec I, Klawe JJ, Tafil-Klawe M, Jeske K, Laudencka A, Bielicka B, Manitius J, Zlomańczuk P. Prevalence of sleep apnea syndrome in hemodialyzed patients with end-stage renal disease. J Physiol Pharmacol. 2006;57(4):207-11.

5. Nicholl DD, Ahmed SB, Loewen AH, Hemmelgarn BR, Sola DY, Beecroft JM, Turin TC, Hanly PJ. Diagnostic value of screening instruments for identifying obstructive sleep apnea in kidney failure. J Clin Sleep Med. 2013:9(1):31-8.

6. Young T, Palta M, Dempsey J, Skatrud J, Weber S, Badr S. The Occurrence of Sleep-Disordered Breathing among Middle-Aged Adults. N Engl J Med. 1993;328(17):1230-5

7. Peppard PE, Young T, Barnet JH, Palta M, Hagen EW, Hla KM. Increased Prevalence of Sleep-Disordered Breathing in Adults. Am J Epidemiol. 2013; 177(9):1006-14.

8. Lee $\mathrm{Y}-\mathrm{C}$, Hung $\mathrm{S}-\mathrm{Y}$, Wang $\mathrm{H}-\mathrm{K}$, Lin C-W, Wang H-H, Chen S-W, Chang M-Y, Ho L-C, Chen Y-T, Liou H-H, et al. Sleep Apnea and the Risk of Chronic Kidney Disease: A Nationwide Population-Based Cohort Study. Sleep. 2014 38(2):213-21.

9. Kang EW, Abdel-Kader K, Yabes J, Glover K, Unruh M. Association of sleepdisordered breathing with cognitive dysfunction in CKD stages 4-5. Am J Kidney Dis. 2012;60(6):949-58.

10. Sharma SK, Agrawal S, Damodaran D, Sreenivas V, Kadhiravan T, Lakshmy R, Jagia P, Kumar A. CPAP for the Metabolic Syndrome in Patients with Obstructive Sleep Apnea. N Engl J Med. 2011;365(24):2277-86.

11. Campos-Rodriguez F, Peña-Griñan N, Reyes-Nuñez N, De la Cruz-Moron I, Perez-Ronchel J, De la Vega-Gallardo F, Fernandez-Palacin A. Mortality in obstructive sleep apnea-hypopnea patients treated with positive airway pressure. Chest. 2005;128(2):624-33.

12. Roumelioti ME, Buysse DJ, Sanders MH, Strollo P, Newman AB, Unruh ML. Sleep-disordered breathing and excessive daytime sleepiness in chronic kidney disease and hemodialysis. Clin J Am Soc Nephrol. 2011:6(5):986-94.

13. Kimmel PL, Miller G, Mendelson WB. Sleep apnea syndrome in chronic renal disease. Am J Med. 1989:86(3):308-14.

14. Hallett M, Burden S, Stewart D, Mahony J, Farrell P. Sleep apnea in endstage renal disease patients on hemodialysis and continuous ambulatory peritoneal dialysis. ASAIO J. 1995;41(3):M435-41.

15. Sakkas GK, Gourgoulianis Kl, Karatzaferi C, Liakopoulos V, Maridaki MD, Pastaka C, Lavdas E, Soher BJ, Dovas S, Fezoulidis I, et al. Haemodialysis patients with sleep apnoea syndrome experience increased central adiposity and altered muscular composition and functionality. Nephrol Dial Transplant. 2008;23(1):336-44

16. Jung HH, Lee JH, Baek HJ, Kim SJ, Lee JJ. Nocturnal hypoxemia and periodic limb movement predict mortality in patients on maintenance hemodialysis. Clin J Am Soc Nephrol. 2010:5(9):1607-13.

17. Sakaguchi Y, Shoji T, Kawabata H, Niihata K, Suzuki A, Kaneko T, Okada N, Isaka Y, Rakugi H, Tsubakihara Y. High Prevalence of Obstructive Sleep Apnea and Its Association with Renal Function among Nondialysis Chronic 
Kidney Disease Patients in Japan: A Cross-Sectional Study. Clin J Am Soc Nephrol. 2011;6(5):995-1000.

18. Beecroft JM, Hoffstein V, Pierratos A, Chan CT, McFarlane PA, Hanly PJ. Pharyngeal narrowing in end-stage renal disease: implications for obstructive sleep apnoea. Eur Respir J. 2007;30(5):965-71.

19. Sanders MH, Newman AB, Haggerty CL, Redline S, Lebowitz M, Samet J, O'Connor GT, Punjabi NM, Shahar E. Sleep and Sleep-disordered Breathing in Adults with Predominantly Mild Obstructive Airway Disease. Am J Respir Crit Care Med. 2003;167(1):7-14.

20. Tang SCW, Lam B, Lai ASH, Pang CBY, Tso WK, Khong PL, Ip MSM, Lai KN. Improvement in Sleep Apnea during Nocturnal Peritoneal Dialysis Is Associated with Reduced Airway Congestion and Better Uremic Clearance. Clin J Am Soc Nephrol. 2009;4(2):410-8.

21. Elias RM, Chan CT, Paul N, Motwani SS, Kasai T, Gabriel JM, Spiller N, Bradley TD. Relationship of pharyngeal water content and jugular volume with severity of obstructive sleep apnea in renal failure. Nephrol Dial Transplant. 2012;28:937-44.

22. Adult obstructive sleep apnea task force of the American academy of sleep medicine. Clinical Guideline for the Evaluation, Management and Long-term Care of Obstructive Sleep Apnea in Adults. J Clin Sleep Med. 2009;5(3):263-76.

23. Erman MK, Stewart D, Einhorn D, Gordon N, Casal E. Validation of the ApneaLink ${ }^{\text {TM }}$ for the Screening of Sleep Apnea: a Novel and Simple SingleChannel Recording Device. J Clin Sleep Med. 2007;3(4):387-92.

24. Levey AS, Bosch JP, Lewis JB, Greene T, Rogers N, Roth D. Modification of Diet in Renal Disease Study Group. A more accurate method to estimate glomerular filtration rate from serum creatinine: a new prediction equation. Ann Intern Med. 1999;130(6):461-70.

25. Flemons WW, Littner MR, Rowley JA, Gay P, Anderson WM, Hudgel DW, McEvoy RD, Loube DI. Home diagnosis of sleep apnea: A systematic review of the literature*: an evidence review cosponsored by the american academy of sleep medicine, the american college of chest physicians, and the american thoracic society. Chest. 2003;124(4):1543-79.

26. Hays RD, Kallich JD, Mapes DL, Coons SJ, Amin N, Carter WB, Kamberg C. Kidney Disease Quality of Life Short Form (KDQOL-SFTM), Version 1.3: A Manual for Use and Scoring. Santa Monica: Rand; 1997.

27. Johns MW. A new method for measuring daytime sleepiness: the Epworth sleepiness scale. Sleep. 1991;14(6):540-5.

28. Netzer NC, Stoohs RA, Netzer CM, Clark K, Strohl KP. Using the Berlin Questionnaire to identify patients at risk for the sleep apnea syndrome. Ann Intern Med. 1999;131(7):485-91.

29. Ferber R, Millman R, Coppola M, Fleetham J, Murray CF, Iber C, McCall V, Nino-Murcia G, Pressman M, Sanders M, et al. Portable recording in the assessment of obstructive sleep apnea. ASDA standards of practice. Sleep. 1994:17(4):378-92.

30. Berry RB, Budhiraja R, Gottlieb DJ, Gozal D, Iber C, Kapur VK, Marcus CL, Mehra R, Parthasarathy S, Quan SF, et al. Rules for Scoring Respiratory Events in Sleep: Update of the 2007 AASM Manual for the Scoring of Sleep and Associated Events: Deliberations of the Sleep Apnea Definitions Task Force of the American Academy of Sleep Medicine. J Clin Sleep Med. 2012;8(5):597-619.

31. Miller MR, Hankinson J, Brusasco V, Burgos F, Casaburi R, Coates A, Crapo R, Enright P, van der Grinten CPM, Gustafsson P, et al. Standardisation of spirometry. Eur Respir J. 2005;26(2):319-38.

32. Wabel P, Rode C, Moiss U, Chamney PW, Wizemann V. Accuracy of bioimpedance spectroscopy (BIS) to detect fluid status changes in hemodialysis patients. Nephrol Dial Transplant. 2007;22 Suppl 6:VI129.

33. Tagliabue A, Cena H, Deurenberg P. Comparative study of the relationship between multi-frequency impedance and body water compartments in two European populations. Br J Nutr. 1996;75(01):11-9.

34. Hankinson JL, Odencrantz JR, Fedan KB. Spirometric reference values from a sample of the general U.S. population. Am J Respir Crit Care Med. 1999; 159(1):179-87.

35. Nigam G, Pathak C, Riaz M. A systematic review of central sleep apnea in adult patients with chronic kidney disease. Sleep Breath. 2016;1-8.

36. Unruh ML, Sanders MH, Redline S, Piraino BM, Umans JG, Hammond TC, Sharief I, Punjabi NM, Newman AB. Sleep apnea in patients on conventional thrice-weekly hemodialysis: comparison with matched controls from the Sleep Heart Health Study. J Am Soc Nephrol. 2006;17(12):3503-9.

37. Bucca CB, Brussino L, Battisti A, Mutani R, Rolla G, Mangiardi L, Cicolin A. Diuretics in obstructive sleep apnea with diastolic heart failure. Chest. 2007:132(2):440-6.

\section{Submit your next manuscript to BioMed Central and we will help you at every step:}

- We accept pre-submission inquiries

- Our selector tool helps you to find the most relevant journal

- We provide round the clock customer support

- Convenient online submission

- Thorough peer review

- Inclusion in PubMed and all major indexing services

- Maximum visibility for your research

Submit your manuscript at www.biomedcentral.com/submit

) Biomed Central 